\title{
Design and Feasibility Analyses of Morphing Airfoil Used to Control Flight Attitude
}

\author{
Sha Du* - Haisong Ang \\ College of Aerospace Engineering, Nanjing University of Aeronautics and Astronautics, China
}

Morphing technology, inspired by bat and bird flight can enable an aircraft to adapt its shape to enhance mission performance and optimize flight attitude controlling efficiency. A morphing airfoil concept is proposed to replace the traditional flap, ailerons, elevator and rudders in order to improve aerodynamic efficiency in this paper. A procedure is used to virtually simulate a morphing wing to perform fast, relatively accurately and efficiently. A set of optimal airfoil shapes obtained are aimed at minimizing the aerodynamic drag character by optimizing morphing configurations at different $C_{l}$ under the twodimensional steady-flow simulation. These airfoil shapes are used to maneuver flight attitude, minimize drag and take place of traditional control surfaces of different rolling, yawing and pitching moment. Then, the basic relationships between optimized morphing airfoil and the traditional control element on rolling, pitching and yawing moment are simplified to the relationship of $C_{l}$. The morphing airfoil shapes at different $C_{l}$ are represented. The configuration of traditional airfoil and morphing airfoil at different $C_{l}$ are compared. It is proved that morphing wing can be used to take the place of a traditional wing. (C)2011 Journal of Mechanical Engineering. All rights reserved.

Keywords: morphing wing, deformation institutions, traditional control surface, aerodynamic character, optimal design, compare

\section{INTRODUCTION}

Since the Wright brothers' first successful flight, aircraft designers have been focusing on improving the aircraft flight efficiency, and especially airline companies are anxious to improve the commercial aircraft efficiency nowadays. Usually aircraft wings are designed to be most efficient at cruising flight but suffer performance penalties under other conditions, such as taking off, landing and controlling flight attitude. Inspired by the bald eagle which can change its own flap configuration to fit different flight conditions and control the rolling, pitching and yawing performance [1] many researchers have investigated different ways to change the flight efficiency in different environments. Many research works have been published on smart wing and morphing aircraft technique in recent years.

Morphing wing technology can be used to control flow on aircraft wing [2], change the deform of shock wave [3], deform the shape of aircraft wing to make the aircraft be the most efficient at different flight speed [4], control the aircraft roll by twisting a flexible wing on a fullsize aircraft [5] and improve the aerodynamic and aero elastic performance of military aircraft [6] to [11].

All the techniques above were used to optimize the airfoils [12] to [16], wings' platform configuration [17] and the three dimension configuration [18] to [20] of the aircraft in order to obtain an optimal aircraft configuration for a fixed design parameter.

Advancements of actuation, sensing technology, the development of adaptive materials (shape memory materials, macro fiber composites flexible matrix composites [21], specially designed skin materials [22] and [23], piezoelectric material and elastic deformation material [24]), the progress of the smart structures [25] to [27], the aerodynamic advances in computational fluid dynamics, optimization techniques, Mathematical Modeling technique and multi-disciplinary design have increased the ability of engineers to improve the morphing wing technology.

The new advances in morphing technology allow aircraft performance to be further increased by obtaining the optimal aircraft configurations not only at different flight attitude [28] and stages [29]. Particularly the morphing technique can be used to control the attitude with the most optimal 
configuration and take the place of traditional elevators.

In this paper, a kind of morphing concept has been proposed which can deform the configuration to different airfoils and controlling the flight attitude with minimize cost. An aerodynamic shape optimization code is used to obtain a set of optimal airfoil shapes to replace the traditional hinged control surfaces at different angle separately. The aerodynamic characters of optimal morphing airfoils and traditional hinged control surfaces (which can be used in flaps, ailerons, elevating and yawing rudders) are compared. The configurations of the set of optimal morphing airfoils will be represented. Then, some conclusions are addressed with comments on the benefits and drawbacks of the morphing airfoil concept.

\section{MATHEMATIC AIRFOIL MODEL}

Numerous mathematic methods have been devised to represent airfoil geometry in aerodynamic design, optimization and parametric studies. In this paper "CST" mathematical method [30] to [32] proposed by Brenda Kulfan is chosen to describe the airfoil configuration; there are $n$ control parameters which can be defined by the customer according to the required accurate which are used to control the different part of airfoil configuration.

The "CST" method is based on Bernstein polynomial of an order $n$, the airfoils are represented by the Eqs. (1) to (3).

$$
\xi(\psi)=\psi^{N_{1}}(1-\psi)^{N_{2}} \sum_{i=0}^{n} A U_{i} S_{r, n}(\psi)+\psi \cdot \xi_{T},
$$

where $\psi=x / c, \xi=z / c, \xi_{T}=\Delta \xi_{T E} / c, A U$ is an array of $n$ numbers, which is the control parameter that can be used to determine the shape of the airfoil.

$$
S_{r, n}(x)=K_{r, n} x^{r}(1-x)^{n-r},
$$

where $r=0$ to $n$ ( $n$ is order of the Bernstein polynomial).

In the above equation, the coefficients factors $K_{r, n}$ are binominal coefficients defined as:

$$
K_{r, n} \equiv\left(\begin{array}{l}
n \\
r
\end{array}\right) \equiv \frac{n !}{r !(n-r) !} .
$$

The Bernstein polynomial representation of the unit shape function, for any order of Bernstein polynomial selected to represent the unit shape function, only the first term defines the leading edge radius and only the last term defines the boat-tail angle. The other in-between terms are "shaping terms" that can only affect the inbetween shape of the leading edge radius and the trailing edge of the airfoils.

\section{THE MORPHING WING CONTROLLER CONCEPT}

The traditional flaps, ailerons, elevators and rudders consist of hinged control surfaces that are attached to the trailing edge of the wing on a fixed-wing aircraft. The ailerons are used to control the aircraft in roll, the two ailerons are typically interconnected, so that one goes down when the other goes up: the down going aileron increases the lift on its wing while the up going aileron reduces the lift on its wing, producing a rolling moment about the aircraft's longitudinal axis [33]. The elevating and yawing rudders are used to control the aircraft in pitch and yaw. All the control elements above can control the flight attitude by changing the lift of the control surfaces, so the flight controlling can be simplified to force on different control elements. Any control element that can change the force of the whole airfoil can take the place of the traditional control element. It has been found that morphing airfoil control element can take the place of the traditional control element and provide a smaller drag.

Morphing airfoil can change the airfoil configuration smoothly by varying the camber, leading edge and trailing edge's configuration and position of initial airfoil, which can lead to the same variation with the traditional control elements of lift coefficient $\left(C_{l}\right)$, drag coefficient $\left(C_{d}\right)$ and the position of aerodynamic center. Therefore, the morphing airfoil theory may be used to replace the traditional hinged control surfaces including ailerons, elevating and vertical rudders.

Take a morphing wing for example whose Mach number is 0.045 , Reynolds number is 300000 , the angle of attack is $5^{\circ}$ and the initial airfoil is NACA0012. Airfoil3 is NACA0012 with a control surface under an angle of attack 
which can provide a $C_{l}$ 0.6940.The airfoil NACA0012 (airfoil 1 in Fig 1.a) can change its own configuration to different shapes, such as airfoil2 showed in Fig. 1a, to increase the $C_{l}$ with a smaller $C_{d}$ punishment. Airfoil2 is obtained with the target $C_{l}$ the same with the airfoil3 and minimum drag by the optimization process.

a)

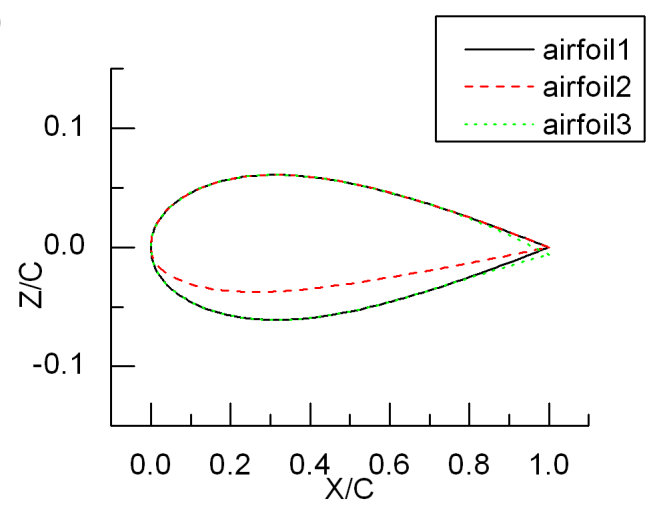

b)

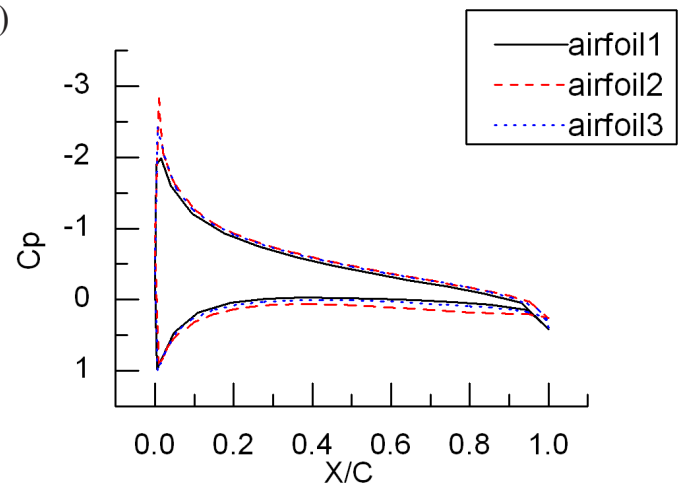

Fig. 1. Configuration and pressure compare of a) morphing airfoil and b) traditional airfoil

Table 1. $C_{l}$ and $C_{d}$ of different airfoil shape Mach number is 0.045, Re is 300,000 and the angle of attack is $5^{\circ}$

\begin{tabular}{|l|c|c|c|}
\hline \multicolumn{1}{|c|}{ Airfoil shape } & $C_{l}$ & $C_{m}$ & $C_{d}$ \\
\hline NACA0012 & 0.6042 & -0.0070 & 0.00120 \\
\hline Morphing airfoil & 0.6940 & -0.0026 & 0.00136 \\
\hline Airfoil3 & 0.6940 & -0.0231 & 0.00147 \\
\hline
\end{tabular}

Table 1 shows the aerodynamic character of the initial airfoil NACA0012 (airfoill in Fig. 1a), morphing airfoil (airfoil2 in Fig. 1a) and the airfoil with an angle of hinged control surface (airfoil3 in Fig. 1a and Table 1). The morphing airfoil and the flap were compared, as showed in Table $1 C_{d}$ of the morphing airfoil is much smaller than $C_{d}$ of traditional flap when they get the same $C_{l}$. According to the character above it is assumed that the morphing wing can replace the traditional hinged control surfaces to control the flight attitude and improve aerodynamic efficiency.

Fig. $1 \mathrm{~b}$ shows the pressure on airfoill and airfoil2, the pressure on upper surface of airfoill is bigger than the pressure on upper surface of the airfoil2, and the pressure on the lower surface of airfoill is smaller than the pressure between the lower surface of airfoil2 at the same flight speed and environment. Therefore, the pressure difference of upper and lower surface in airfoill is smaller than airfoil2, which means that airfoil2 can get a bigger lift than airfoil1.

In order to test whether the morphing airfoil can take the place of the traditional flap, the $C_{d}$ of the traditional control surface and the morphing wing will be compared at different $C_{l}$.

\section{STRUCTURE CONCEPTUAL DESIGN}

There are two basic morphing concepts in the development of a morphing wing: one is changing the surface configuration of the wing [34] and the other is deforming the section shape (the airfoil shape) of the morphing wing [35] and [36].

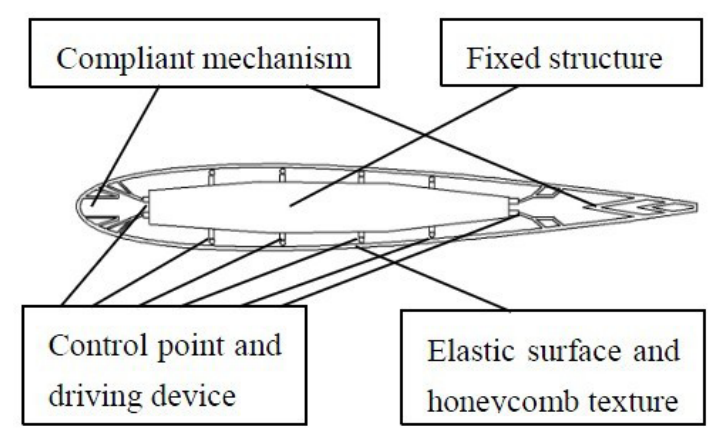

Fig. 2. The morphing structure concept

In Fig. 2, the morphing airfoil compliant concept that can change the section shape is present, which can deform the configuration of the leading edge, trailing edge, and the chamber to fit flight environment and control the attitude. It is axial symmetry about the chord and consists of: 
i. Skin material

The skin material of the morphing airfoil should endure elastic deformation and have high strains. The shape memory polymer was initially considered, but it is useless for the morphing system as the complexity and the shape memory polymer cannot endure high load.

The nature rubber skin together with the thin honeycomb texture can endure elastic deformation and have high strains. Their position is controlled by the control points in the area between the leading and trailing edge to finish configuration deformation.

ii. Compliant mechanism

The compliant mechanism is used on the leading and the trailing edge of the morphing airfoil to complete the airfoil deformation [37] to [40]. The compliant mechanism is optimized according the initial shape and the final shapes.

The two couple control points at the leading and trailing edge are used to control the shape of the compliant mechanism by changing their own position; it can control the configuration of the airfoil together with the eight control points in the upper and lower surface.

iii. The fixed structure

The fixed structure is used to carry the controller of the control points and fix the wing chord together and to the fuselage.

\section{OPTIMIZATION OF THE MORPHING AIRFOIL}

The optimization of the morphing airfoil is necessary in order to compare the morphing airfoils and the traditional hinged control surfaces. The airfoil was optimized to get the optimal airfoil shapes which can provide the same $C_{l}$ with a much smaller $C_{d}$ punishment than any other shapes. To achieve this, a tool that can search the optimal airfoil geometry is used. First the generic constrain was represent by Eqs. (1) to (3) based on the Bernstein polynomial. Second, the XFOIL program is used to get the polar ratio of the airfoil shape in the aerodynamic analysis. Then, the polar ratio is compared with the target parameter and the ratio of the former ones and the airfoil shape control parameter which will be used in the next cycle obtained with Isight.

The XFOIL use the steady Euler equations in integral form to represent the inviscid flow, the compressible lag-dissipation integral method to represent the boundary layers and wake and the incompressible potential flow via the surface transpiration model to calculate the limited separation regions of the viscous solution. Results from XFOIL have been compared against experimental data with good agreement [41].

Isight is a solution that provides engineers with a suite of visual and flexible tools for creating simulation process flows-consisting of a variety of applications, including commercial CAD/ CAE software, internally developed programs, and Excel spreadsheets - in order to automate the exploration of design alternatives and identification of optimal performance parameters. Isight enables users to automate simulation process flows and leverage advanced techniques such as Design of Experiments, Optimization, Approximations, and Design for Six Sigma to thoroughly explore the design space. Advanced, interactive postprocessing tools allow engineers to explore the design space from multiple points of view.

The aerodynamic shape optimization is carried out with the sequential quadratic programming, constrained algorithm SQPDONLP (a sequential quadratic programming optimization method in Isight). The purpose of the SQP-DONLP is the minimization of a differentiable real function subject to inequality and equality constrains. This method builds a quadratic approximation to the Lagrange function and linear approximations to all output constraints at each iteration, starting with the identify matrix for the Hessian of the Lagrangian, and gradually updating using the BFGS (Broydon-FletcherGoldfarb-Shanno) method. On each iteration, a quadratic programming problem is solved to find an improved design, until the final convergence to the optimum design.

The aerodynamic shape optimization problem can be stated as Minimize drag coefficient with regard to a confirmed lift coefficient. Fig. 3 is a flowchart that illustrates the implementation of the aerodynamic shape optimization tool. The code can be summarized as follows: 
i. Represent the airfoils using the Bernstein polynomial of an order $n$.

ii. Change the airfoil control parameter $\left(A U_{i}\right)$ according to the required polar ratio.

iii. Compute the aerodynamic character of the airfoil obtained from step 2 .

iv. Compare the $C_{l}$ and $C_{d}$ of the different airfoils obtained and get the most optimized airfoil with regard to a constant $C_{l}$.

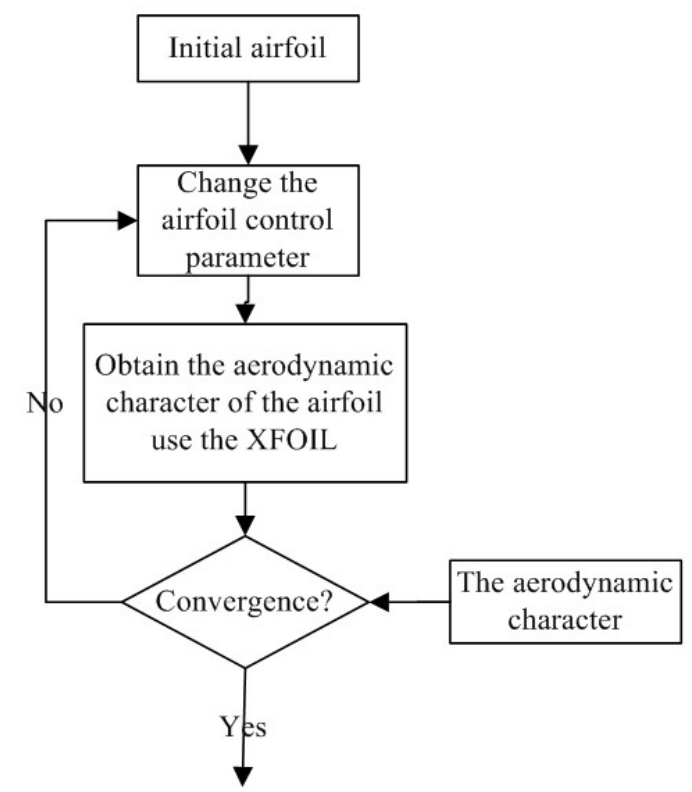

Fig. 3. Wing aerodynamic shape optimization flow chart

\section{RESULTS AND DISCUSSION}

A set of optimal airfoil shapes which can provide different $C_{l}$ with the minimum drag are obtained by the procedure at Mach $0.045, R e$ 300000. In 5.1, the particular polar characteristics of the optimal airfoil configurations are compared with the traditional hinged control surfaces which include a different angle of attack and hinged control surfaces. In 5.2, the optimal airfoil shapes are obtained by the procedure limited by a minimum drag coefficient at different $C_{l}$ which correspond with the different angle of traditional hinged control surfaces, the optimal airfoil shapes can take place of all the control surfaces of a flight. In 5.3, the configuration and pressure versus chord of the airfoil with control surfaces at the angle of attack $5^{\circ}$ and morphing airfoil shapes at the angle of attack $0^{\circ}$ are compared when they provide the same lift coefficient.

\subsection{Aerodynamic Optimization Results}

In a confirmed flight environment, the lift coefficient of a wing is primarily the result of its angle of attack and shape (in particular its camber) of the airfoil. A set of morphing airfoil shapes are optimized to get the best Lift-to-drag ratio based on different $C_{l}$ at different angle of attack and angle of traditional hinged control surfaces of a confirmed airfoil. The airfoil NACA0012 and the optimal airfoil shapes at the speed of Mach 0.045, $\operatorname{Re} 300,000$ at angle of attack 3 and $5^{\circ}$ separately are compared.

Fig. 4 shows the relationship between $C_{l}$, $C_{d}$ of the traditional hinged control surfaces and the optimal morphing airfoils, Flap 0, Flap 3, Flap 5 show the polar ratio character followed with the changing angle of hinged control surface when the angle of attack is 0,3 and $5^{\circ}$ separately. Morphing airfoil show the polar ratio character followed with the deforming configuration of the morphing airfoil.

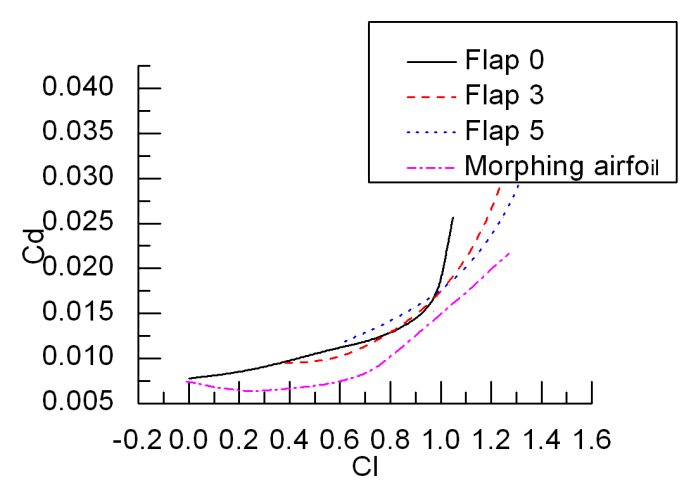

Fig. 4. The relationship between, $C_{b}, C_{d}$ of the traditional flap and morphing airfoil

i. Flap 0 in Fig. 4 shows the polar ratio of the traditional airfoil followed with the changing hinged flap angle at the attack angle $0^{\circ}$. When the $C_{l}$ is smaller than 0.97 , the drag coefficient will increase slowly followed with the increasing $C_{l}$, which is determined by the angle of hinged control surface when the lift coefficient is smaller than 0.97 . Followed by the increasing hinged angle the pressure drag 
will increase quickly when the trailing edge position is beyond the horizontal position of the maxim thickness of the airfoil (the lift coefficient is bigger than 0.97).

ii. If the $C_{l}$ is smaller than 0.35 , according to the Bernoulli equation the morphing airfoil can change the camber of the lower surface to increase the $C_{l}$, which can decrease the cross section area to decrease the pressure Drag and lead to the decrease of $C_{d}$ followed with the increasing $C_{l}$. Otherwise, if $C_{l}$ is bigger than 0.35 , the morphing airfoil cannot provide enough $C_{l}$ by changing the camber only, the trailing edge position had to be altered to increase $C_{l}, C_{d}$ will increase followed with the increasing $C_{l}$.

iii. The $C_{d}$ of the traditional hinged control surface at different angle of attack $(0,3$ and $5^{\circ}$ ) is bigger than the $C_{d}$ provided by the optimal morphing airfoils at the same $C_{l}$. The polar curve of traditional hinged control surface have a different turning point at different angle of attack, $C_{d}$ will increasing slowly if $C_{l}$ is smaller than the turning point, otherwise $C_{d}$ will increasing rapidly. The turning point at the attack angle $0^{\circ}, 3^{\circ}, 5^{\circ}$ is $C_{l}=0.97, C_{l}=1.05, C_{l}=1.15$ separately.

The relationship between $C_{l}, C_{d}$ of the traditional flap and morphing airfoils is axially symmetric about the line of $C_{l}=0$. The relationship between $C_{l}, C_{d}$ when the $C_{l}<0$ can be obtained according to Fig. 5 .

It is more efficient to use a morphing wing to take the place of the traditional hinged control surfaces on the flaps, ailerons, elevators and rudders.

As the aircraft rolls, adverse yaw is caused primarily by the change in drag on the left and right wing. The difference in drag on each wing produces the adverse yaw. There is also an additional adverse yaw contribution from a difference in profile drag between the upaileron and down-aileron. The morphing airfoil can provide the same control parameter with the traditional hinged control element with a smaller drag punishment. Therefore, the morphing airfoil can decrease the adverse yaw caused by the drag.

\subsection{Configuration of the Morphing Airfoil}

A set of airfoil optimal configurations, optimized at Mach 0.045, Re 300,000, are showed in Fig. 5. Figs. 5a to $5 \mathrm{c}$ show the configurations of airfoill to airfoillo, $C_{l}$ of airfoil 1 to 10 increase from low to high.

a)

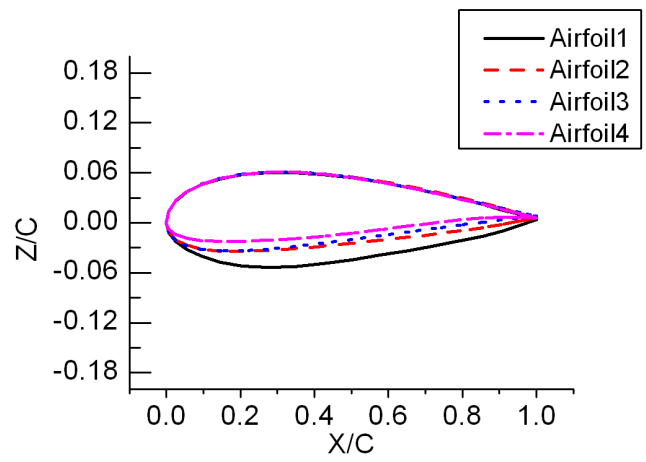

b)

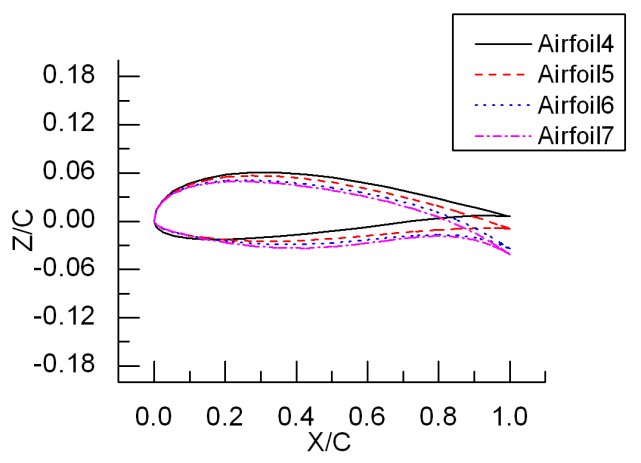

c)

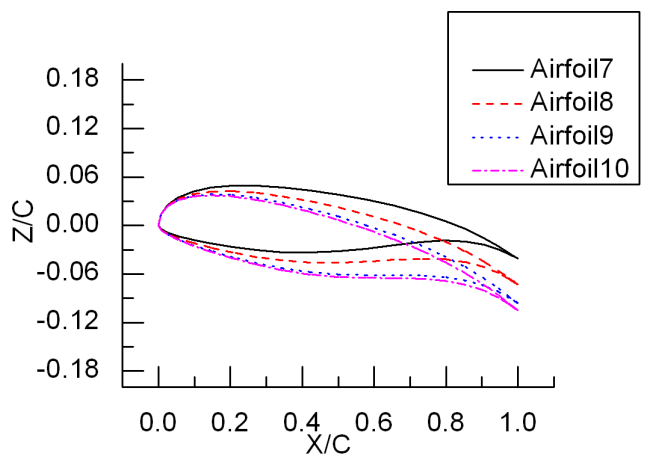

Fig. 5. A set of the optimal airfoil shape and the pressure vs. $x$ axis

The camber and thickness of the optimal airfoil (airfoill to airfoil4) will decrease followed with the increasing lift coefficient if $C_{l}$ is smaller than 0.35 , but followed with the increasing $C_{l}$ (if $C_{l}$ is bigger than 0.35 ), the morphing airfoil 
Couple 1

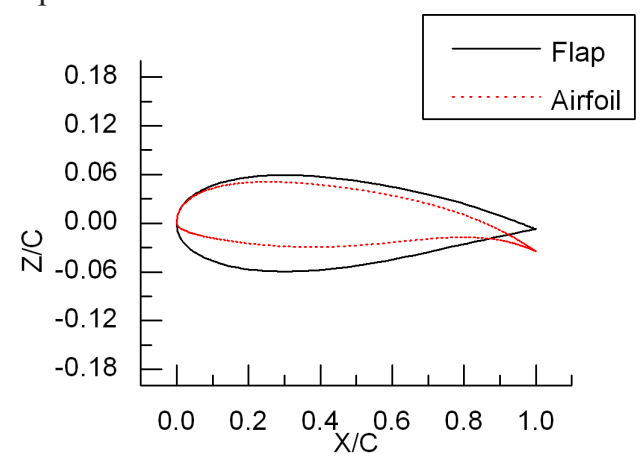

Couple 2

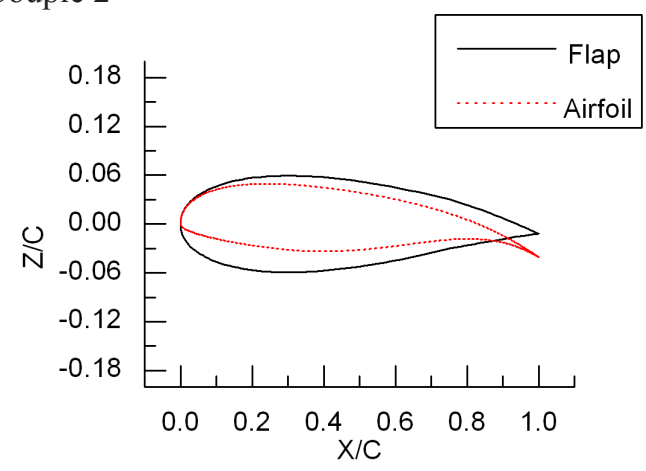

Couple 3

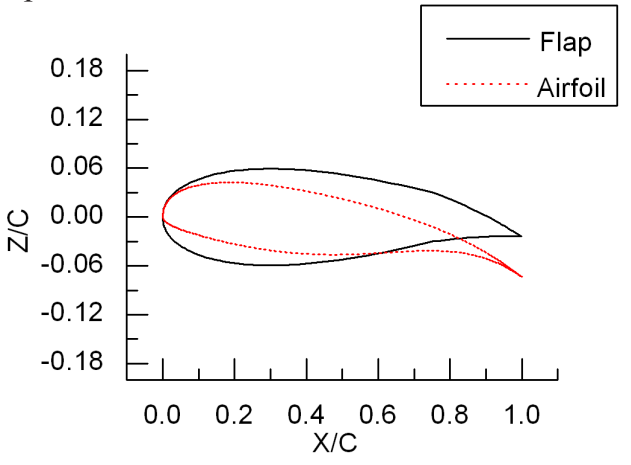

Couple 4

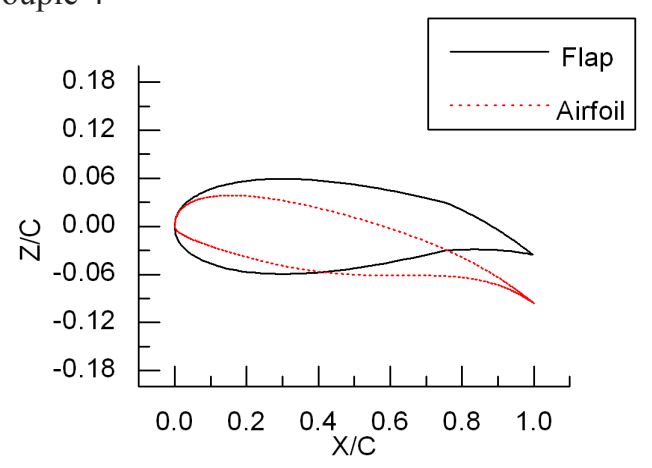

Couple 5

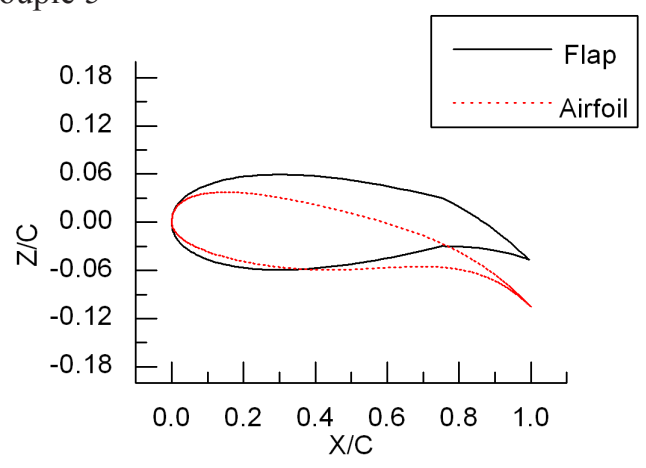

Couple 6

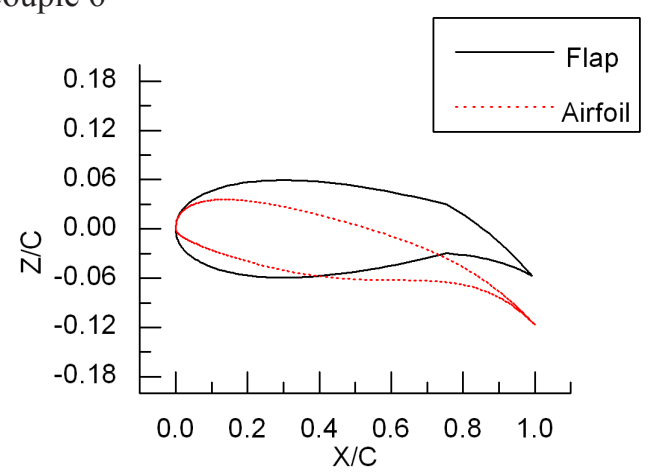

Fig. 6. The morphing and traditional airfoil shape

cannot provide enough $C_{l}$ by changing the camber of the airfoil only, so it is necessary to change the position of trailing edge. The airfoil from airfoil5 to airfoil10 can provide $C_{l}$ by not only changing the camber but also change the trailing edge position of the airfoil.

\subsection{Comparison of the Shape and Pressure}

Six couples of traditional control surface airfoils and the optimal airfoils at different $C_{l}$ are represented in Fig. 6. The traditional control surfaces have different angle of control surface at the angle of attack $5^{\circ} . C_{l}$ and $C_{d}$ of the 6 couples in Fig. 6 are represented in Table 2.

Table 2 shows $C_{l}$ and $C_{d}$ in a different couple of Fig. 6. $C_{d 1}$ is the traditional hinged surface at angle of attack $5, C_{d 2}$ is the morphing airfoil at angle of attack $0^{\circ}$. 
Table 2. $C_{l}$ and $C_{d}$ in different couple of Fig. 6

\begin{tabular}{|c|c|c|c|}
\hline The Fig. no. & $C_{l}$ & $C_{d 1}$ & $C_{d 2}$ \\
\hline Couple 1 & 0.66 & 0.0125 & 0.00781 \\
\hline Couple 2 & 0.75 & 0.01323 & 0.00885 \\
\hline Couple 3 & 0.90 & 0.01555 & 0.01301 \\
\hline Couple 4 & 1.01 & 0.01814 & 0.01512 \\
\hline Couple 5 & 1.15 & 0.02362 & 0.01991 \\
\hline Couple 6 & 1.25 & 0.02766 & 0.02164 \\
\hline
\end{tabular}

\section{CONCLUSION}

The morphing wing is designed according to the morphing airfoil theory represented. It has been proved that the morphing airfoil can replace the hinged control surfaces to control the rolling, pitching and yawing moment with a smaller drag and increasing the flight efficient at different rolling, pitching and yawing moment.

The morphing airfoil control element can reduce the drag from 20 to $60 \%$ (showed in Fig. 5) than the traditional airfoils with control surface when they provide a same $C_{l}$, if the $C_{l}$ is bigger than 0.1 . The morphing airfoil can lead to a smaller adverse yaw when they provide the same rolling moment.

A multidisciplinary design optimization tool was developed to design a morphing wing for an experimental MAV in order to improve and quantify its controlling performance. The configuration of the airfoils is represented clearly, and the configure variation regulation followed with $C_{l}$ is discussed. The detail of the relationship between $C_{l}$ and the control parameter of the airfoil should be researched more and it would be better if it was represented as an equation in the future.

Future work stages will include designing morphing mechanism details, materials and further wind-tunnel test of the morphing wing at different flight speeds and attitude controlling requirement.

\section{REFERENCES}

[1] Bowman, J., Sanders, M.B., Weisshaar T. (2002). Evaluating the impact of morphing technologies on aircraft performance. 43rd AIAA/ASME/ASCE/AHS/ASC Structures
Structural Dynamics and Materials Conference, p. 22-25.

[2] Stanewsky, E. (2001). Adaptive wing and flow control technology. Progress in Aerospace Sciences, vol. 37, no. 7, p. 583667, DOI:10.1016/S0376-0421(01)00017-3.

[3] Siclari, M.J., Nostrand, W., Austin, F. (1996). The design of transonic airfoil sections for an adaptive wing concept using a stochastic optimization method. 34th Aerospace Sciences Meeting and Exhibit, p. 15-18.

[4] Gamboa, P., Lau, F.J.P., Vale, J., Suleman, A. (2009). Optimization of a morphing wing based on coupled aerodynamic and structural constrains. American Institute of Aeronautics and Astronautics (AIAA) Journal, vol. 47, no. 9, p. 2087-2104.

[5] Yurkovich, R.N. (2009). Analysis of the integration of active aeroelastic wing into a morphing wing. 50th AIAA/ASME/ASCE/ AHS/ASC Structures Structural Dynamics and Materials Conference, p. 4-7.

[6] Weisshaar, B.T., Sanders, B. (2002). Evaluating the impact of morphing technologies on aircraft performance. 43rd AIAA/ASME/ASCE/AHS/ASC Structures Structural Dynamics and Materials Conference, p. 22-25.

[7] Florance, P.J., Burner, A.W., Gary, A.F., Hunter, C.A. (2003). Contributions of the NASA Langley Research Center to the DARPA/AFRL/NASA/NORTHROP Grumman Smart Wing Program. 44th AIAA/ ASME/ASCE/AHS Structures Structural Dynamics and Materials Conference, p. 7-10.

[8] Larson, R.R. (1966). Flight Control System Development and Flight Test Experience With the F-111 Mission Adaptive Wing Aircraft. NASA Technical Memorandum 88265.

[9] Hardy, R. (1983). AFTIF-111 mission adaptive wing technology demonstration program, AIAA-1983-1057.

[10] Smith, S.B., Nelson, D.W. (1990). Determination of the aerodynamic characteristics of the mission adaptive wing. Journal of Aircraft, vol. 27, no. 11, p. 44-46, DOI:10.2514/3.45965.

[11] Wrobleski, M.S., Henderson, J. (2005). BAC 1-11 and MAW F-111 Control Surface Weight Estimation for SWIFT Study. $46^{\text {th }}$ AIAA/ 
ASME/ASCE/AHS/ASC Structures Structural Dynamics Materials Conference, p. 18-21.

[12] Huyse, L., Padula, S., Lewis, R., Li, W. (2002). Probabilistic approach to free-form airfoil shape optimization under uncertainty. American Institute of Aeronautics and Astronautics (AIAA) Journal, vol. 40, no. 9, p. 1764-1772, DOI:10.2514/2.1881.

[13] Namgoong, H., Crossley, W.A., Lyrintzis, A.S. (2002). Global optimization issues for transonic airfoil design. 9th AIAA/ISSMO Multidisciplinary Analysis and Optimization Conference, p. 4-6.

[14] Lee, S.W., Kwon, O.J. (2006). Robust airfoil shape optimization using design for six sigma. Journal of Aircraft, vol. 43, no. 3, p. 843-846, DOI:10.2514/1.17359.

[15] Winnemoller, T., van Dam, C.P. (2007). Design and numerical optimization of thick airfoils including blunt trailing edges. Journal of Aircraft, vol. 44, no. 1, p. 232-240, DOI:10.2514/1.23057.

[16] Secanell, M., Suleman, A. (2005). Numerical evaluation of optimization algorithms for low reynolds number aerodynamic shape optimization. American Institute of Aeronautics and Astronautics (AIAA) Journal, vol. 43, no. 10, p. 2262-2267, DOI: $10.2514 / 1.12563$.

[17] Peigin, S., Epstein, B. (2007). Multipoint aerodynamic design of wing-body configurations for minimum drag. Journal of Aircraft, vol. 44, no. 3, p. 971-980, DOI: $10.2514 / 1.26746$.

[18] Nadarajah, S.K., Jameson, A., Alonso, J.J. (2002). Sonic boom reduction using an adjoint method for wing-body configurations in supersonic flow. 9th AIAA/ISSMO Multidisciplinary Analysis and Optimization Conference, p. 4-6.

[19] Reuther, J., Alonso, J., Jameson, A., Eimlinger, M., Saunders, D. (1999). Constrained multipoint aerodynamic shape optimization using an adjoint formulation and parallel computers: Part 1. Journal of Aircraft, vol. 36, no. 1, p. 51-60, DOI:10.2514/2.2413.

[20] Reuther, J., Alonso, J., Jameson, A., Eimlinger, M., Saunders, D. (1999), Constrained multipoint aerodynamic shape optimization using an adjoint formulation and parallel computers: Part 2. Journal of Aircraft, vol. 36, no. 1, p. 61-74, DOI:10.2514/2.2414.

[21] Tobushi, H., Hara, H., Yamada, E., Hayashi, S. (1996). Thermomechanical properties in a thin film of shape memory polymer of polyurethane series. Smart Materials and Structures, vol. 5, no. 4, p. 483-491, DOI:10.1088/0964-1726/5/4/012.

[22] Reich, G.W., Sanders, B., Joo, J.J. (2007). Development of Skins for Morphing Aircraft Applications via Topology Optimization. The 48th AIAA/ASME/ASCE/AHS/ASC Structures Structural Dynamics and Materials Conference, p. 23-26.

[23] Thill, C., Etches, J., Bond, I., Potter, K., Weaver, P. (2008). Morphing skins. Aeronautical Journal, vol. 112, no. 1129, p. 117-139.

[24] Murray, G., Gandhi, F., Bakis, C. (2007). Flexible matrix composite skins for onedimensional wing morphing. 48 th AIAA/ ASME/ASCE/AHS/ASC Structures Structural Dynamics and Materials Conference, p. 2326.

[25] Moniz, P.A.A. (2005). Adaptive aeroelastic aircraft structures. Ph.D. Thesis, Univ. Técnica de Lisboa, Lisbon.

[26] Perkins, D.A., Reed, J.L.Jr., Havens, E. (2004). Morphing wing structures for loitering air vehicles. The 45th AIAA/ASME/ASCE/ AHS/ASC Structures Structural Dynamics and Materials Conference, p. 19-22.

[27] Bilgen, O., Kochersberger, K., Diggs, E.C., Kurdila, A.J., Inman, D.J. (2007). Morphing wing micro-air-vehicle via macro-fibercomposite actuators. The 48th AIAA/ASME/ ASCE/AHS/ASC Structures Structural Dynamics and Materials Conference, p. 2326.

[28] Rusnell, M.T., Gano, S.E., Pérez, V.M., Renaud, J.E., Batill, S.M. (2004). Morphing UAV Pareto curve shift for enhanced performance. The 45th AIAA/ASME/ASCE/ AHS/ASC Structures Structural Dynamics and Materials Conference, p. 87-95.

[29] Gano, S.E., Renaud, J.E. (2002). Optimized unmanned aerial vehicle with wing morphing for extended range and endurance. The 9th AIAA/ISSMO Multidisciplinary Analysis and Optimization Conference, p. 45-56. 
[30] Kulfan, B.M., Bussoletti, J.E. (2006). Fundamental Parametric Geometry Representations for Aircraft Component Shapes, AIAA-2006-6948.

[31] Kulfan, B. M.(2007). A Universal Parametric Geometry Representation Method - "CST". AIAA-2007-0062.

[32] Kulfan, B.M. (2007). "CST" universal parametric geometry representation method with applications to supersonic aircraft. $4^{\text {th }}$ International Conference on Flow Dynamics, p. 26-28.

[33] Kermode, A.C., Barnard, R.H. (1972). Mechanics of flight. Pitman Publishing Ltd., London.

[34] Lee, D.H., Weisshaar, T.A. (2005). Aeroelastic studies on a folding wing. $46^{\text {th }}$ AIAA/ASME/ ASCE/AHS/ASC Structures Structural Dynamics and Materials Conference, p. 1821.

[35] Gandhi, N., Jha, A., Monaco, J. (2007). Intelligent control of a morphing aircraft. 48th AIAA/ASME/ASCE/AHS/ASC Structures Structural Dynamics and Materials Conference, p. 112-128.

[36] Lafountain, C., Cohen, K., Abdallah, S. (2009). Camber controlled airfoil design for morphing UAV. 47th AIAA Aerospace
Sciences Meeting Including The New Horizons Forum and Aerospace Exposition, p. 211-218.

[37]Lu, K.J., Kota, S. (2002). Compliant Mechanism Synthesis for Shape-Change Applications: Preliminary Results. Smart Structures and Materials Proceedings of SPIE, vol. 4693.

[38] Santer, M., Pellegrino, S. (2009). Topological optimization of compliant adaptive wing structure. American Institute of Aeronautics and Astronautics (AIAA) Journal, vol. 47, no. 3, DOI:10.2514/1.36679.

[39] Trease, B.P., Kota, S. (2006). Synthesis of Adaptive and Controllable Compliant Systems with Embedded Actuators and Sensors. ASME 2006 International Design Engineering Technical Conferences \& Computers and Information in Engineering Conference, p. 10-13.

[40]Lu, K.J., Kota, S. (2003). Design of compliant mechanisms for morphing structural shapes. Journal of Intelligent Material System and Structures, vol. 14, DOI:10.1177/10453890305563.

[41] Drela, M., Youngren, H. (2001). XFOIL 6.94 User Guide, self-published, Cambridge. 